\title{
Machine Learning And Statistical Theory Enabled Real Time People Analytics Framework Based On Emotional Quotient Intelligence And Self Efficacy
}

\author{
D.N.Kalpana, A.Thomas Paul Roy, S.Sathees Babu
}

\begin{abstract}
The motivation behind the examination was to concentrate the connection between Emotional Intelligence (E.I.) and Self-Efficacy (S.E.) with statistic factors in the Public members in Madurai and Dindigul. This review was illustrative. The general public comprised of thousand ranges and the example was 120 who were haphazardly chosen. Enthusiastic Intelligence Inventory was utilized as an tool. Relationship, t-test and relapse were utilized to examination of information. Comes about demonstrated that there was critical connection between E.I. also, S.E emphatically. There were not discovered noteworthy contrasts amongst operational and authoritative; and prepared and untrained persons in Emotional Intelligence and Self-Efficacy. Plus, Emotional Intelligence was anticipated by statistic factors and Self-Efficacy and the other way around. Passionate Intelligence and Self-Efficacy have common association with each other.
\end{abstract}

Keywords: Emotional, Self Efficacy, haphazardly, public members, Madurai, Enthusiastic and Passionate.

\section{INTRODUCTION}

Passionate insight is a standout amongst the most critical mental components that can expand workers capacity and upgrade their employment execution. Representatives who have a higher passionate knowledge can deliver higher quality items and administrations in their workplace. In the meantime, improve passionate knowledge can prompt build proficiency and efficiency of representatives. Some investigates uncovered that those feelings have appropriately coordinated, can prompt more prominent responsibility and expanding self-viability and effectiveness of association7. Enthusiastic knowledge can influence on work climate, work fulfillment, effective administration and hierarchical improvement (Porter, 2014, cited by Jain and Sinha, 2015)6. Constitutions of associations require communications among people. These connections have association with the execution of occupation obligations, for example, giving

administrations to customers, get guidelines and answer to the heads, collaboration and coordination with partners. Jordan (2012) accepted that the passionate duty of the general population is an important segment of social connections5. They demonstrated that accomplishment at work related with positive feelings in which it speaks to the instructing passionate insight in the working environment is basic.

Passionate knowledge can be a huge effect on different human exercises, for example, instruction, preparing, authority and direction of others, individual life, emotional well-being and prosperity (Siaruchi with, 2014). Since passionate insight can be enhanced via preparing, along these lines, preparing will be exceptionally valuable in the association (Bar-On, 2007)8.

Social correspondence, critical thinking aptitudes, general wellbeing and self-viability can be viable factors to upgrade the enthusiastic knowledge of workers (Kar, 2006, Jain and Sinha, 2015)9.

\section{RELATED WORK}

As indicated by Bar-On, passionate knowledge is an arrangement of capacities, capability and non-subjective aptitudes that influence individual's capacity to be fruitful in managing ecological necessities and weights. It incorporates five interior segments (enthusiastic mindfulness, decisiveness, sense of pride, self-completion and autonomy), three individual parts (sympathy, social duty and relational connections), two similarity segments (critical thinking, reality and adaptability evaluation quality), two segments of pressure control (stretch resilience and motivation control), and two segments of general state of mind (joy and self-expectation). As it were, enthusiastic insight alludes to aptitudes and capacities that incorporate the capacity of individual and others feeling control, the refinement amongst them and usage of data to guide contemplations and activities. Along these lines, it is one of the imperative elements deciding the accomplishment of individual that will be utilized for powerful adjustment .

Revised Version Manuscript Received on 10, September 2019.

D.N.Kalpana, Assistant Professor, Department of Computer Science and Engineering, PSNA College of Engineering and Technology, Dindigul, Tamilnadu, India. (Email: kalpanahere10@gmail.com)

Dr.A.Thomas Paul Roy, Assistant Professor, Department of Computer Science and Engineering, PSNA College of Engineering and Technology, Dindigul, Tamilnadu, India. (Email: pauli.dgl@ gmail.com)

Mr.S.Sathees Babu, Associate Professor, Department of Computer Science and Engineering, PSNA College of Engineering and Technology, Dindigul, Tamilnadu, India. (Email: ssbabu@psnacet.edu.in). 


\section{MACHINE LEARNING AND STATISTICAL THEORY ENABLED REAL TIME PEOPLE ANALYTICS FRAMEWORK BASED ON EMOTIONAL QUOTIENT INTELLIGENCE AND SELF EFFICACY}

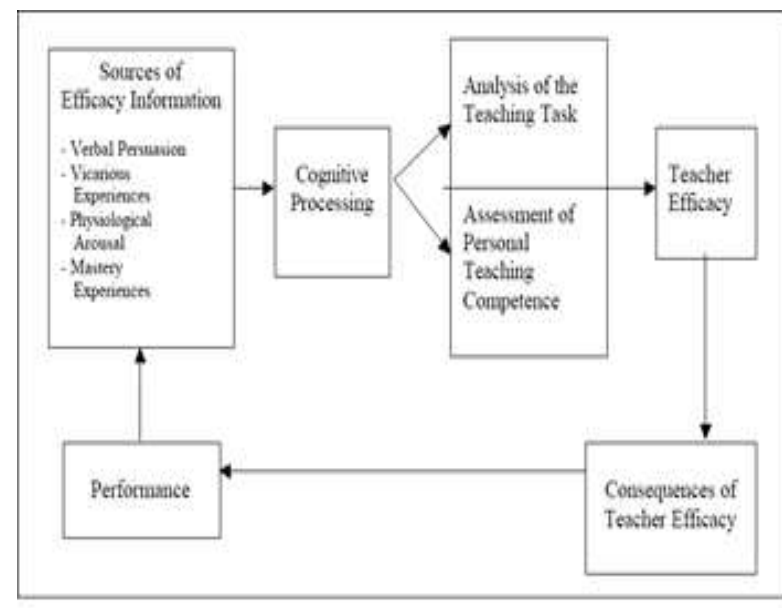

Fig 1: SELF EFFICACY STRUCTURE

In purpose of social intellectual view, self-viability alludes to convictions and judgments of a man about his capacity in performing obligations and duties (Albert Bandura,2007). Additionally, enthusiastic insight joined with other essential determinants, for example, conditions (a man's capacity to prevail with regards to adapting to ecological necessities), an organic common arrangement, psychological ability, learning, realities and imperatives of the earth variable (Aminiha 2015)10.
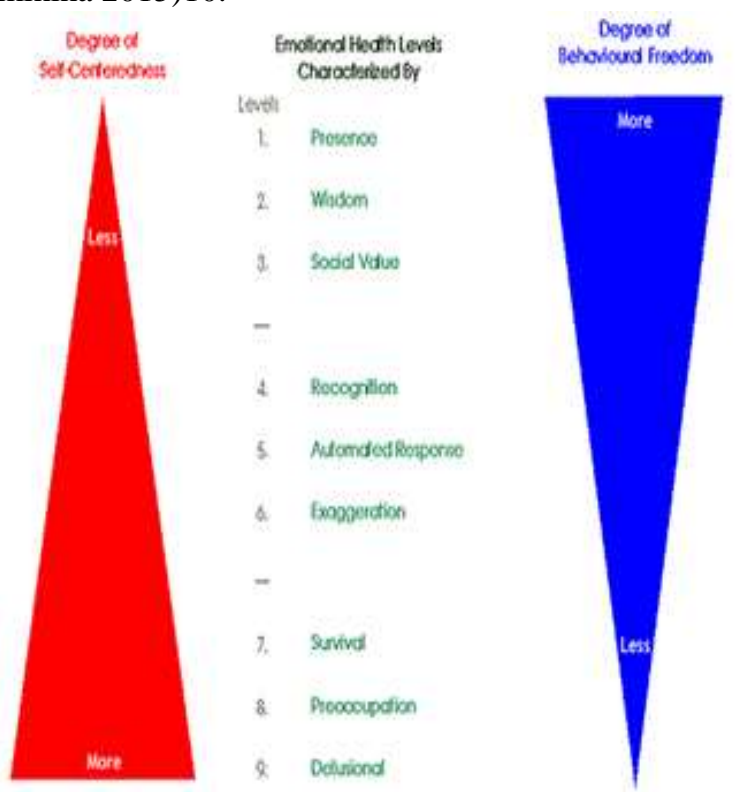

Fig 2: DEGREE OF EI

Zahraei (2008) revealed that passionate knowledge preparing had critical and positive effect on occupation fulfillment of representatives of Iranian Engineering and Manufacturing Marine Installation Company. Abdolmaleki (2010) 1 found that there are connections between passionate insight elements and nature of work existence with efficiency. Mashhadi and partners (2010) reasoned that passionate knowledge has an adverse association with the indications of marginal identity issue. Farzadnia (2011)2 found that there is huge and posict administration styles in Milad Hospital,. In addition, there is a huge and positive connection between collaboration styles and hesitance. Barsad (2000) in his learns about passionate cognizance comprehended that creating positive feelings inside gatherings encourage collaboration between individuals, diminish struggle, and enhance productivity 3 .

Nelis with (2009) demonstrated that enthusiastic knowledge preparing for representatives significantly affects expanding passionate character and capacity to deal with their feelings. Salami (2010) learned about the part of passionate knowledge, self-viability4, and mental well-s and demeanors and found that these factors enhance the nature of graduate instruction. Yazic with (2011) examined about passionate insight and self-viability as indicators of scholastic accomplishment demonstrated that age, sex, and self-adequacy are achievements8.

Besides, measurable outcomes uncovered that there is intelligent impact between age, scholastic accomplishment and socio - monetary status of understudies. At the end of the day, the logical progression of ladies was essentially higher than men.

\section{The EQ Quadrant}

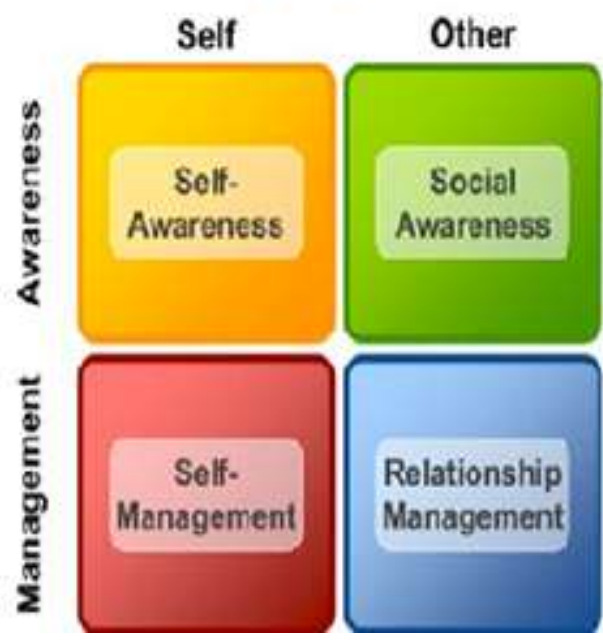

Fig 3 EQ Measure Structure

Specified inquires about unmistakably have demonstrated the significance of enthusiastic insight and self-viability however there are a couple studies which accentuation on fondness of passionate knowledge and self-adequacy with employment execution and staff viability.

The gotten effects for research need aid comparable of the outcomes from claiming fallowing studies; Jamshinejhad (2001), regarding benefit and enthusiastic intelligence, Zahraei (2008) in regards Enthusiastic brainpower and particular occupation fulfillment in iranian building and Manufacturing marine establishment agency employees, Mashhadi with (2010)9, in the field of association between Enthusiastic brainpower Furthermore outskirt personality, Farzadnia (2011), in the field of Enthusiastic brainpower Also clash oversaw economy styles, Barsad (2010), in regards relationship between constructive feeling Furthermore expanding cooperation, Nelis with (2009), around Enthusiastic brainpower preparing and capacity on management, salami (2010), applicable of the part of enthusiastic intelligence, self- efficacy, Furthermore prosperity in (2011) in the field from claiming Enthusiastic 
brainpower What's more self -efficacy. However, the comes about of Yazic (2011)5 around Enthusiastic brainpower identified with those agdistis What's more sex might have been diverse with those comes about of this study.

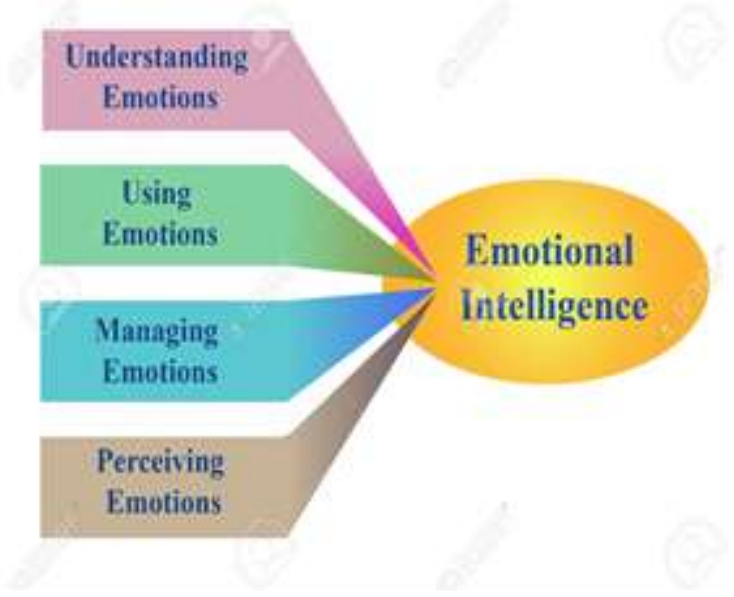

Fig 4: EI STRUCTURE

\subsection{Video Position}

The points of this review were:

1. To decide the connection between enthusiastic knowledge and self-viability of staff.

2. To foresee passionate insight without anyone else viability.

3. To test contrasts between enthusiastic insight and self-adequacy of staff in operational and managerial areas.

4. To investigate contrasts between enthusiastic insight and self-adequacy of prepared and untrained staff.

5. To foresee passionate insight by statistic factors and self-adequacy.

6. To foresee self-adequacy by statistic factors and passionate insight.

\subsection{Model}

Look into speculation are as per the following:

1. There is connection between enthusiastic insight and self-adequacy.

2. Emotional knowledge can be anticipated without anyone else's input adequacy.

3. There is distinction between passionate insight and self-adequacy of staff in operational and regulatory.

4. There is contrast between passionate insight and self-adequacy of prepared and untrained staff.

5. The adequacy.

6. self-adequacy can be unsurprising by statistic factors and passionate insight.

\section{METHOD}

\subsection{Data}

This study might have been spellbinding What's more investigated those association the middle of Enthusiastic brainpower Also self - viability with chosen demographic variables done Bahman engine particular organization staff to 2011. Those examine populace included 2000 male Also female workers. Example of 120 were haphazardly chose out about 280 disappointments and outrage on his/her staff who were attempting done suspension manufacturing area. When finishing those questionnaire, the subjects were guaranteed that the data held in the questionnaire might stay totally private.

\subsection{Tools}

1. Questionnaire about Individual-Occupational Information: this questionnaire might have been comprised of 14 inquiries.

2. Questionnaire for enthusiastic Intelligence: this questionnaire might have been reasoned for 90 inquiries Furthermore might have been readied Eventually Tom's perusing Bar-On (1997). It need 5 scales (intrapersonal skill, interpersonal skill, adaptability, anxiety management, Also Concerning illustration 0. 95 Furthermore its dependability might have been affirmed Eventually Tom's perusing a couple psychologists. Each subject got an aggregate score for questionnaire.

3. Self-Efficacy Inventory: this stock might have been furnished by Schroder with clinched alongside 1982. Those first versify might have been. Consisted of 36 questions in the present study its validity coefficient by 0.86 and its Dependability might have been affirmed by a couple psychologists. Every staff acquired an aggregate score of the stock.

\section{3. Factual System.}

Spellbinding Furthermore inferential detail (t-test, man correlation, Also multi variable regression) were utilized on examination from claiming information.

\section{IMPLEMENTATION}

The real data set can be collected from the Madurai District as well as the Dindigul district's public persons. The face expression and the voice modulation can evaluated using the central tendency measures like mode, median, Range , variance, standard deviation, and standard error .An emotional quotient as well as the Self efficacy can be measured using the Dispersion measures and the Distribution measures.

This video analytics case study is the extended work of my research .The video captured from public sector depends on the questionnaires and the replies from various mindset personalities. Video's expressions differed one from another. Video analyzed using the EM Tool (Emotional Measurement Tool) .Numerical indicators related to the EI and Self Efficacy.

Today, an evolving set of Video Management Practices (VMP) in libraries has grown tremendously in research and publication. By exploring and expanding from the previous research that has found to have a significant impact and gaps in VMP, this work intends to propose a conceptual framework of VMP at Madurai. This work emphasizes the core of video processes such as Video Create (VCr), Video Acquisition (VAc), Video Capture (VCa), and Video Sharing (VSh). However, Video Record (VRe) and Video Preserving (VPr) are the new processes and are expected to have a positive relation to VMP and as borne out in this research.

The Prediction of Emotional Intelligence of citizens in 


\section{MACHINE LEARNING AND STATISTICAL THEORY ENABLED REAL TIME PEOPLE ANALYTICS FRAMEWORK BASED ON EMOTIONAL QUOTIENT INTELLIGENCE AND SELF EFFICACY}

India by using Video analytic Techniques. The conjoint effect of the Emotional Intelligence, Mental Health and Adjustment towards with their family life among Indian citizens. This Chapter explains the EM Search Tool to Step up the degree level of Emotional Intelligence.

Each video analytics solution will work a bit differently depending on the creator and application. They all work in the same basic way, however - when setting up the application, set up parameters to the activity the EM tool is looking for, set up the alert notification system, and when the tool detects something that meets its search criteria it alerts .

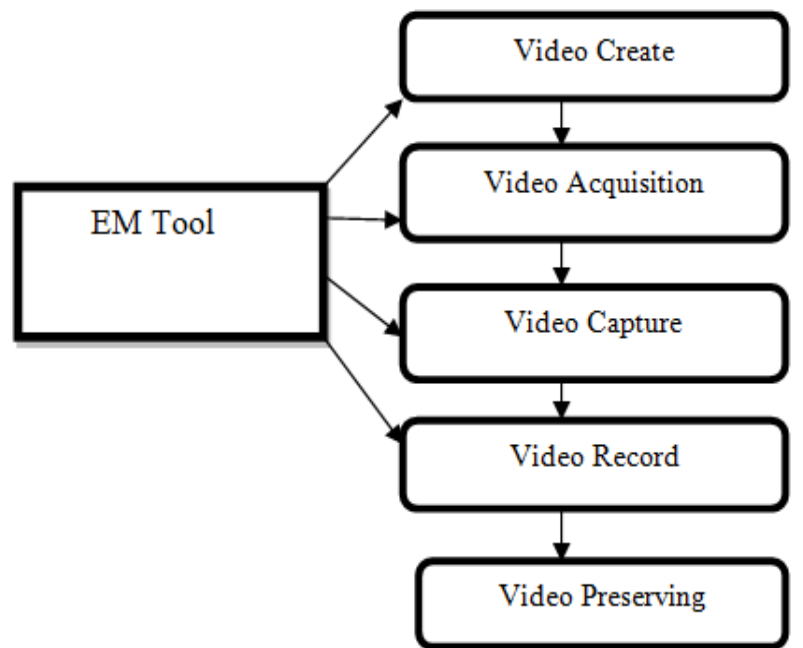

Fig 5 Video Analytics flow diagram

\section{RESULTS AND DISCUSSIONS}

Major share of the test aggregation (34. $2 \%$ ) were at those extend for 26-30 years; $88.3 \%$ men; $77.5 \%$ married; $62.5 \%$ for b. Sc. Degree or higher; 54. $16 \%$ experts; 54. $17 \%$ managerial and $45.83 \%$ operational staff, Also 66. 7\% prepared staff. Therefore, bosses provide preparing offices to white collar .Furthermore secondary training level staff in place to upgrade their Enthusiastic brainpower What's more self-efficacy. Generally, a standout amongst the imperative reasons behind these outcomes could make clarified by being low levels about staff inspiration Furthermore interest applicable with their occupation obligations. Instruction and employment title Similarly as two chosen demographic variables bring indicated critical Furthermore certain association with self-efficacy. Thus, disappointments and outrage on his/her staff with higher training level required higher self-efficacy.

Table 1: Numerical indicators related to Emotional Intelligence and Self-Efficacy

\begin{tabular}{|c|c|c|c|c|c|c|c|c|}
\hline \multirow[t]{4}{*}{ Variable } & \multicolumn{5}{|c|}{$\begin{array}{l}\text { Dispersion } \\
\text { Events }\end{array}$} & \multicolumn{3}{|c|}{ Distribution Actions } \\
\hline & Mode & Median & Mean & Range & Variance & $\begin{array}{l}\text { Standard } \\
\text { Error }\end{array}$ & $\begin{array}{l}\text { Coefficient of } \\
\text { Skewness }\end{array}$ & $\begin{array}{l}\text { Coefficient } \\
\text { of Kurtosis }\end{array}$ \\
\hline & 375 & 318 & 318.28 & 199 & 20.01 & 12.88 & -15.26 & 0.2222 \\
\hline & 168 & 97 & 97.98 & 96 & 81.05 & 10.71 & 0.019 & 0.0173 \\
\hline
\end{tabular}

Table No. 1 showed that there was a slight difference among mode, median and mean, since the rate of skewness and kurtosis index were less than 1, therefore, the above distribution supported the assumption of normality and mean could be used as the representative of the index of central inclination and also the models of parametric statistics.

As Table No. 2 has shown that there is positive and significant correlation between emotional intelligence and self-efficacy. So the first and second hypotheses were accepted.

\begin{tabular}{|c|c|c|c|c|c|c|c|c|}
\hline \multirow[t]{2}{*}{ Variable } & \multicolumn{3}{|c|}{$\begin{array}{l}\text { Central Tendency } \\
\text { Measures }\end{array}$} & \multicolumn{2}{|c|}{$\begin{array}{l}\text { Dispersion } \\
\text { Events }\end{array}$} & \multicolumn{3}{|c|}{ Distribution Actions } \\
\hline & Mode & Median & Mean & Range & Variance & $\begin{array}{l}\text { Standard } \\
\text { Error }\end{array}$ & $\begin{array}{c}\text { Coefficient of } \\
\text { Skewness }\end{array}$ & $\begin{array}{l}\text { Coefficient } \\
\text { of Kurtosis }\end{array}$ \\
\hline $\begin{array}{c}\text { Emotional } \\
\text { Intelligence }\end{array}$ & 375 & 318 & 318.28 & 199 & 20.01 & 12.88 & -15.26 & 0.2222 \\
\hline Self Efficacy & 168 & 97 & 97.98 & 96 & 81.05 & 10.71 & 0.019 & 0.0173 \\
\hline
\end{tabular}


Table 3: Mean differences between Emotional Intelligence and Self- Efficacy of staff with respect to the departments and the training status

\begin{tabular}{ccccccc}
\hline Variables & $\begin{array}{c}\text { Departments \& } \\
\text { Training Status }\end{array}$ & Mean & & $\mathbf{t}$ & $\begin{array}{c}\text { Degree of } \\
\text { Freedom }\end{array}$ & $\begin{array}{c}\text { Significance } \\
\text { Level }\end{array}$ \\
\hline $\begin{array}{c}\text { Emotional } \\
\text { Intelligence }\end{array}$ & Prepared & 359.06 & 1.30 & 0.74 & 176 & 0.91 \\
& Executive & 397.89 & 1.39 & & & \\
Self Efficacy & Operational & 167.64 & 7.49 & -0.86 & 156 & 0.77 \\
& Managerial & 168.44 & 7.91 & & & \\
Emotional & skilled & 391.74 & 9.78 & 1.96 & 158 & 0.349 \\
Intelligence & Unqualified & 395.05 & 3.20 & & & \\
& & & & 1.95 & 148 & 0.285
\end{tabular}

$\mathrm{t}$ values in Table No. $3(\mathrm{t}-0.64, \mathrm{t}=-0.56, \mathrm{t}=1.16, \mathrm{t}=1.05)$ revealed that there are not found significant differences between emotional intelligence and self efficacy of staff in different departments(operational and administrative) and different training status. Therefore, the third and fourth hypotheses were rejected.

Table 4: Multivariate regression, prediction of emotional intelligence by age, sex, marital status, education level, job title, income, and self - efficacy

\begin{tabular}{lllll}
\hline $\begin{array}{l}\text { Sum of } \\
\text { Square } \\
\text { s }\end{array}$ & $\begin{array}{l}\text { Degree } \\
\text { of } \\
\text { Freedom Squares }\end{array}$ & $\begin{array}{c}\text { Mean } \\
\text { of }\end{array}$ & & $\begin{array}{l}\text { Level of } \\
\text { Significance }\end{array}$ \\
\hline & & 78.1 & \\
& & 4 & 0.021
\end{tabular}

With respect to F value (28.14) cited in Table No 4 that is significant ( it could be said that emotional intelligence can be predicted generally by age, sex, marital status, education level, job title, income, and self-efficacy. Thus, the fifth hypothesis was accepted.

Table 4-a: Regression coefficient in related to table No 4; prediction of emotional intelligence by age, sex, marital status, education level, job title, income, and self - efficacy

\begin{tabular}{|c|c|c|c|c|c|}
\hline Predicted Variable & $\begin{array}{c}\text { Independent } \\
\text { variable } \\
\end{array}$ & $\overline{\mathbf{B}}$ & Beta & $\mathbf{t}$ & Significance Level \\
\hline \multirow{3}{*}{$\begin{array}{l}\text { Emotional } \\
\text { Intelligence }\end{array}$} & Time & -0.819 & & -1.926 & 0.98 \\
\hline & Gender & -1.917 & & -0.253 & 0.89 \\
\hline & Marital Status & 0.102 & & 0.183 & 0.76 \\
\hline & learning & -7.524 & & -2.437 & $0.025 *$ \\
\hline & Job Title & -3.153 & & -1.355 & 0.28 \\
\hline & profits & 3.766 & & 1.777 & 0.18 \\
\hline & Self Efficacy & 3.994 & & 13.86 & $0.021 *$ \\
\hline
\end{tabular}

Table 4- a showed that there is significant and negative Besides, significant relationship is found between selfefficacy and emotional intelligence positively. relationship between education and emotional intelligence.

Table 5: Multivariate regression, rediction

\begin{tabular}{cccccc}
\hline & $\begin{array}{c}\text { Sum of } \\
\text { Squares }\end{array}$ & $\begin{array}{c}\text { level of } \\
\text { Freedom }\end{array}$ & $\begin{array}{c}\text { Mean } \\
\text { of Squares }\end{array}$ & F & $\begin{array}{c}\text { Intensity of } \\
\text { Significance }\end{array}$ \\
\hline Decay & 5634.228 & 9 & 5634.228 & 88.17 & 0.0981 \\
Residual & 7631.738 & 12 & 93.498 & & \\
Total & 7265.96 & 179 & & & \\
& & & & & \\
\hline
\end{tabular}

F value (28.17) cited in Table No. 5, indicated that there is

significant relationship .

F value (28.17) cited in Table No. 5, indicated that there is significant relationship . between self-Efficacy and selected demographic variables. So, self-efficacy can be predicted by age, sex, marital status, education level, job title, income, and between selfemotional intelligence. Therefore, the sixth hypothesis was accepted. 


\section{MACHINE LEARNING AND STATISTICAL THEORY ENABLED REAL TIME PEOPLE ANALYTICS FRAMEWORK BASED ON EMOTIONAL QUOTIENT INTELLIGENCE AND SELF EFFICACY}

Table 5-a: Regression coefficient

\begin{tabular}{cccccc}
\hline Predicted Variable Independent Variable & B & Beta & t & \multicolumn{2}{c}{$\begin{array}{l}\text { Significance } \\
\text { Level }\end{array}$} \\
\hline & Time & 0.121 & 0.019 & 1.1186 & 0.2138 \\
Gelf-Efficacy & 0.881 & 0.0218 & 0.4176 & 0.6133 \\
& Marital Status & 1.010 & 0.0514 & 0.7186 & 0.4133 \\
& learning & 2.069 & 0.2713 & 2.7198 & $0.0016^{*}$ \\
& Job Title & 1.129 & 0.1612 & 2.0101 & $0.0148^{*}$ \\
& Profits & 0.695 & 0.0916 & -1.2172 & 0.2106 \\
\hline
\end{tabular}

Figures in Table 5-a indicated that there are significant and positive relationships between education, job title, emotional intelligence and self-efficacy.

\section{CONCLUSION}

Overall, there are no critical contrasts the middle of prepared alternately untrained, Also Additionally operational or managerial disappointments and outrage on his/her staff Previously, Enthusiastic brainpower and self-efficacy. There will be a certain Also critical relationship the middle of Enthusiastic brainpower and self-efficacy. Enthusiastic brainpower could a chance to be predicted Toward age, sex, education, conjugal status, payment, What's more self-efficacy. It is discovered critical and negative relationship the middle of Enthusiastic brainpower Furthermore training. It implies that an individual with An higher training need an easier Enthusiastic brainpower. Self-efficacy may be predicted by age, sex, education, conjugal status, income, and Enthusiastic brainpower. Self-efficacy need a noteworthy and sure relationship with training. It might make inferred that an individual for higher training need a higher self-efficacy. Conversely, it need An critical and negative association for salary. It methods higher wage goes for easier self- viability. It cam wood be closed that there are not noteworthy contrasts Around disappointments and outrage on his/her staff because of section Furthermore preparation status. Beside, Enthusiastic brainpower and self-efficacy would two coordinated circuit variables which need aid extremely critical Components so as on improve wellbeing What's more Push work execution about representatives. Instruction Concerning illustration a standout amongst those chosen demographic variables need huge and negative association for Enthusiastic brainpower about staff, that is, an individual with An higher training need an easier Enthusiastic brainpower. It appears to be higher instructed representatives in this production line required low inspiration will accomplish vocation advancement. Maybe, they were working in the not particular occupation positions balanced for their educations alternately particular majors. Also, disappointments and outrage on his/her staff for higher employment titles need higher self-efficacy. Obviously, it could a chance to be said that work title/job position could assistance of the staff will show All the more self-efficacy in the fill in put. Enthusiastic brainpower might make demonstrated clinched alongside bunch connection same time self-efficacy will a chance to be watched in.

\section{REFERENCES}

1. Abdolmaleki, J. Study of relationship between emotional intelligence and quality of life with productivity; Case
2. International Management Conference. Aryana Industrial Research Group, Tehran.

3. Aminiha, A. Relationship between emotional intelligence and matrimony. M.A Thesis. Education and Psychology Faculty, Alzahra university, Tehran, Iran. (2005).

4. Bar-On, R. The emotional quotient inventory (EQ-I): A measure of emotional intelligence. Toronto. Canada: Multi-Health System. Barsade,S. G.(2000). The ripple effect: Emotional contagion in groups . Yale University press. .(2010).

5. Farzadnia, Farzaneh. The relationship between emotional intelligence and collaboration and compromise styles among head nurses in Milad Hospital. (2011)

6. Journal of Agricultural Science and Technology (JAST), Vol. 4, No. (19), pp. 119-134. (2011)

7. Hure, Y., Berg, P \& Wilderom, C. Transformational leadership as a mediator between emotional intelligence and team outcomes. The Leadership Quarterly, LEAQUA00732;pp. 13. . (2011)

8. Jain, A . K \& , Sinha , A . K . General health in organization : Relative relevance of emotional intelligence, trust, and organizational support . ( 2015 )

9. International Journal of Stress Management , 12 ,pp. 257 273 . ( 2015 )

10. Jamshidnejhad, E. Comparetive study of work stress and job satisfaction of school and high school principles. M.A Thesis. Education and Psychology Faculty, Allame Tabatabaei University, Tehran, Iran. (2010).

11. Jordan, p. , Ashkanasy, N. , Hartel, C. , and Hooper, G.. Work groupemotional intelligence Scale development and relationship to team process effectiveness and goal focus. Human Resource Management Review, 12, pp.195 214. (2012)

12. Kar, A. Positive psychology, happiness science and human powers. Translated by $\mathrm{H}$, Pashasharifi, J, Najafizand, and B. Sanaeizaker. Sokhan Publication, Tehran, Iran. (2016).

13. Mashhadi, Ali. Relationship between emotional intelligence and symptom of borderline personality disorder. Journal of Fundamentals of Mental Health, Vol. 12, No.1(45), pp. 390-9. (2010).

14. Mayer, J . and Peter Salovey, The Intelligence of Emotional Intelligence Journal of Intelligence . (2010). 